\title{
Topicality of Linguistic Competence and Performance Teaching at Higher Educational Institutions of the Russian Federation (on the Example of RANEPA)
}

\author{
Nadezhda Nikolaevna Prudnikova ${ }^{1}$ \\ ${ }^{1}$ Russian Presidential Academy of National Economy and Public Administration (RANEPA), Russia \\ Correspondence: Nadezhda Nikolaevna Prudnikova, Russian Presidential Academy of National Economy and \\ Public Administration (RANEPA), Russia. E-mail: nadkap1@yandex.ru
}

Received: January 31, 2016 Accepted: February 15, 2016 Online Published: March 28, 2016

doi:10.5539/ijel.v6n2p99 URL: http://dx.doi.org/10.5539/ijel.v6n2p99

\begin{abstract}
The topic and importance of linguistic competence, performance and significance of a modern methodology in teaching writing skill, is highlighted for higher educational institutions of the Russian Federation. Transdisciplinary approach and interactive method are viewed as the most efficient ways of performance formation. Writing is regarded as cognitive mechanism of linguistic competence development. Significance of writing skills is explained by new educational standards of Russia and its integration into the European Higher Education Area. Paramount importance of writing skills is determined by shift of the higher educational institutions of the RF to the grant earning activity connected with composing many documents such as application letters, reports, blogs, e-mails, different forms, working papers, articles in the international repositories. Creative writing is presented as the most complex and effective way of EFL teaching.
\end{abstract}

Keywords: linguistic competence, performance, interactive method, transdisciplinary approach, EFL competence, ESP competence, writing skills, EFL writing activity

\section{Introduction}

The highly developed and modern economies of the West are characterized by innovation and "knowledge economy". Economy and social sphere institutions of the well-developed countries are being transformed in alignment with current business cycles and environmental changes, modification of the conditions of socio-economic development and intellectual essence of industry influence both qualitative and quantitative aspects of production controls.

Emerging trends, economic changes and growth are connected to educational strategies "Human capital" (Sun-Keung Pang, 2013, p. 19) skills and capability development.

The main goal of the governmental activity on innovative economic policy improvement is increasing the significance of the higher education (Brovko, 2008, p. 127). Competitiveness of the higher educational institutions graduates are determined by their "global thinking" (Osipov \& Ziyatdinova, 2015, p. 141) based on the human values, principles of citizenship, ability to further education and development as well as self-upbringing.

The necessity of EFL competence formation in the modern world is indisputable.

\section{Theoretical Background}

Successful educational systems of different countries in globalization era are characterized by several factors:

1) ability to view needs of the students of different age groups during the period of their study and further education on the life-long basis;

2) application of educational standards relevant for several countries;

3 ) technological support of the distant learning systems;

4) unified system of competences assessment;

5) shrewd management in the sphere of education. 
Changes to curricula of the higher educational institutions are explained in the new educational standards under the conditions of the Russian Federation integration into global education.

EFL (English as a Foreign Language) competence presupposes different parameters; moreover, they are constantly changing.

The following principles are highlighted:

- life-long learning;

- correct differentiation of the groups of students in accordance with their: age group, educational level, way of cognition (i.e., communicative oriented way, cognitive oriented way or mixed way of knowledge acquiring depending on extroverted-oriented or introverted-oriented personality type).

In the Russian Federation linguistic didactics of EFL means different methodical approaches to bachelors' and masters' curricula.

Bachelor's instruction presupposes the principle of personality-oriented teaching and principle of approximation; master's instruction demands principle of functionality and problem-oriented learning.

Methods of bachelor's trainings include the principle of simplification, speech accent instead of thorough grammar study, principle of native language usage and simulation. Methods of master's training mean principle of ESP (English for Specific Purposes), principle of functionality and principle of absence of translation.

Common didactic principles for both levels of two-tier learning (bachelor's degree-master' degree) are principles of activity, personal development, clear instruction, intensive teaching, professional-oriented learning, system and application-oriented approach.

Common methodical principles for bachelor's and master's are communicative teaching, differentiation, inter-cultural communication, and synthesis of teaching productive and receptive types of speech practice, case-study organization of training and problem-oriented study.

Personality improvement during EFL learning means development of tolerance and respect towards representatives of other cultures.

Principle of development means acquiring cognitive means of communicative and epistemological activities. The result of this goal realization is attention, logics, internal speech, linguistic anticipation, relative forecasting and so on.

Foreign language is compulsory in the bachelor's curriculum irrespective of the profile.

At present linguistic training means communicative intensive method within the transdisciplinary approach. Transdisciplinary approach is used to teach the students how to communicate in a foreign professional environment, that is, it means a gradual acquiring of the ESP competence.

The main principles of such teaching are intensification of the whole period of classes, use of the foreign language as the only language of communication and study of the themes conveying extra-linguistic information relevant to the future profession of the students.

Transdisciplinary approach to foreign language teaching is implemented in interactive training because the format of interactive lesson helps to solve very difficult tasks of EFL competence development, professional competence realization and personality development of the students.

There are four types of transdisciplinary abilities during the linguistic study:

1) cognitive abilities (development of thinking and logical skills),

2) social abilities (understanding of different people, skills of cooperation and tolerance),

3) personal skills (assertiveness, initiative, responsibility, autonomous way of thinking and behavior),

4) organizational skills (ability to plan and fulfill the work according to a certain schedule).

We provide the following classification of the interactive classes during EFL training:

1) according to the functions (current and final control of the formation of EFL, role-plays, learning new material, problem solving);

2) according to the form (lessons in groups of students, working with a computer environment by oneself, multiple-choice tests in a computer class);

3) according to the didactic purposes during EFL competence formation (implementation of the language 
competence and performance in the form of dialogs, writing and communication within role-plays).

Many researchers emphasize the importance of EFL competence at professional level. Numerous research papers reflect the importance of EFL competence, as not a trait of a person from the elicit community, but a necessary skill of all the employees, a must for ordinary persons as well as the literacy characteristic of upper class (Clarke, D. 2012).

It is evident that a good command of the English language provides opportunities to export and import intellectual capital, i.e., academic mobility of lecturers and students, participation in international conferences and involvement in international projects, and mutual programs developments.

The format of the classes and the role of lecturers are changing, the lecturer is now a partner of the audience, less authoritarian and more collaborative. The lecturer has to be an effective communicator, leader and create an environment for collaborative interactions and feedback with the audience.

The foundation for teaching English Language communication must be inclusive, collaborative, interactive information provisioning, and exercises.

The universal method of EFL teaching consist of comprehensive and interactive methods within groups during classes, multimedia is a means of collaboration between participants and objects of communication. (subject-subject and subject-object relations of the student).

Interactive teaching is the synthesis of cognitive and communicative approaches to the formation of EFL competence, effective means of higher educational institutions instruction's optimization, the way of expansion of the educational environment and its adaptation to the quasi-professional communication in a foreign language.

Effective formation of the EFL competence is not possible without implementation of all aspects of speech and linguistic performance (speakers, listeners, writers and readers). The main outcomes of language are cognition (construction of a thought for speaking and writing as productive types of speech performance) and correct interpretation of the other's thoughts (reading and listening as receptive types of linguistic performance). The two way communication process may also be implemented through interactive EFL competence simulations.

It is clear that the comprehension of interactive teaching means direct and indirect cooperation of the participants for effective outcomes of didactic tasks to achieve their full potential. Teaching is not only information exchange, it is exchange of activities, values, ideas, and it is comprehension and interactions between information personalities.

Foreign languages learning requires two obligatory conditions:

1) intense communication at the classes (different forms of interaction of the students and the native speakers, mutual participation in educational and research projects) and

2) representation of educational environment in a foreign language for simulation of authentic situations (for example in case of EFL formation all the elements of educational settings should be in English - manuals, journals, handouts, video and audio materials, visual aids, resources of the web and so on) (Mikhaleva \& Kuznetcova, 2014, p. 349).

Consequently studying elements of linguistic performance is also based on the developing participants' ability to write which is also changing. Speech performance is actively learned in the form of utterances, dialogs, monologs etc. Writing, thus far has not been at the top of the agendas in both school and higher educational institutions' curriculum. Writing is very important in conjunction with the competence-oriented approach of Bachelors' and Masters' instruction introduced in the Russian Federation. Creative writing is now a must for the new educational standards.

Significance of writing skills is determined by the shift of the higher educational institutions to the grant earning activity, connected with writing documents such as application letters, reports, blogs, e-mails, forms, working papers and papers in the international repositories.

Moreover, qualification demands of international exams comprise writing skills at least at the Intermediate level.

Traditional exams on foreign languages within the Russian Federation have historically not included writing. However, exams help in the assessment of cumulative knowledge and the level of comprehension and discourse components of the EFL. Writing skills enhances the ability to express conclusions, explain one's point of view, summarize existing opinions by visualizing your thoughts and responses to any issue, analyze attitudes and build a sequence of arguments in a logical way.

According to some researchers: Sorokina, Konobeeva and Sergeeva etc., writing teaching starts with the 
students' motivation. It is necessary to explain the audience that writing performance is an innovative skill in the modern society. The next step is theory study, learning of compositional characteristics of different writings (CV, annotation, abstract, business letters, essays) as well as following practical implementation of the knowledge.

It is important to understand that teaching writing skills is not a linear process. It is a complex and multi-hierarchical process, the result of this is a shift to communicative variant of texts that should be adapted to the learning process and be closely connected with actual situations of life. This shift is possible only if graphical, spelling skills and the writing technique are integrated.

Modern profile linguistic classes of schools and linguistic faculties of the higher educational institutions pay great attention to the project work. Students always use computer programs for presenting the projects results in the forms of slide shows. Ability to implement ICT in the learning and teaching process is also a must nowadays. In addition, it enhances literacy as well.

Teaching writing assists in the development of speech performance, reading and builds cognitive skills in the foreign language.

The next step is formation of a skill to present one's ideas in a competent way, i.e. formation of a writing skill in a foreign language.

Let us have a look at the writing of essays in more details.

\section{Formation of a Writing Skill in a Target Language}

Students need to demonstrate the ability to think and speak independently, applying available resources to create reliable ideas and conclusions.

Presenting your ideas competently relies on your ability to extract information from multiple sources - research papers, reference books, different kinds of documents, fiction etc. and summarizing the findings in your own words.

Written presentation must clearly portray the writer's message in a manner the reader (or lecturer) will comprehend the message. The awareness of a structure and composition of an essay (introduction, main part, conclusions) is the best way to compose your final written documents. Teaching these structures and explaining the importance of structure connection of thoughts, sentences, logic of narration, expression of language, use of metaphors, reliability of conclusions supporting the theme, enables the reader to comprehend the message.

An essay can also be used as a template for students' independent work after classes and for creating future written texts.

Creative writing is a complex, time-consuming and thoughtful process, and is one of the challenges of the modern linguistic didactics.

An interdisciplinary approach is applied to both learning fiction and creating one's own texts.

According to Gershanova (2011, p. 71), use of Arts and Sciences can help to understand specific traits of a discourse, the point of close interconnection of an author's ideas, content of the text and its interpretation by the reader. Synergetic essence of a text makes writing essay more difficult because the text can generate new ideas reflecting them in a discourse, in communication of the author and the reader. This interaction produces the new sense: the authors' ideas in the individual perception by the reader, depending on the person's character, level of education, cultural, social and age category attitudes. The result may be narrowing or on the contrary expansion of the sense as well as multiplication of the sense in case of several readers and several interpreters.

Still it is necessary to note that notwithstanding the dynamic sense generation every "new" text (the reader's variant of interpretation) is more or less within the reader's conception. The key signals of the original text perform the restrictive role, and the invariant remains in all the readers' interpretations. The linguistic units building the associative verbal structure of a text, creating a model holding a reader within the author's conception and forbidding the excessive interpretation, express key signals.

The axis of a text is a concept, presented by fractals. The essence of a fractal of a text is subjective, that is why a reader (as a subject) is important for generating a sense.

Linguistic representations of the conceptual fractals of a text, finding out the fractals, their positioning around the conceptual centre of the text prove that Sciences and Arts do not contradict each other but generate new ideas and approaches to studying such an object as text. Teaching writing, especially creative one, is impossible without such detailed and thorough analysis.

Fiction has never been learned at the foreign language classes because it has been considered superfluous 
material irrelevant to everyday communication (Ibsen, 1995).

However, it is clear that fiction helps to form coherence, addressed character, logical structure of a discourse (Kenzhalinova, 2012, p. 42).

There are two main approaches of using fiction at the classes - communicative (organized in the form of the students' discussions) and linguistic one (realized by stylistic rules and principles). The first approach presupposes use of fiction for leaning a language, the second approach demands studying the role of a language in literature teaching. Authentic fiction is used for both approaches. Authentic texts have been applied in linguistic didactics for many years but they were either adapted or originally simplified in the forms of schedules, recipes, menus, letters and so on. Learning such materials could form EFL only at threshold level.

Fiction that is not simplified is a precious source of civilization understanding. Lack of "right" answers during literature learning can help a teacher to organize informal discussions, communication of ideas and sense interpretation. Interactive learning of fiction is the most commonly used method. It is realized in the following way. Students present their own text composed on a certain theme, the lecturer demonstrate his or her own variant of a text, all the materials are shown in the format of a slide show. Cooperation of students and a lecturer produces the third variant of a text, and this mutual work helps to build the plot and linguistic means of expression in the best way, corresponding the chosen genre and structure of the text.

\section{Conclusion}

Reading works of fiction, their discussion, analysis and composing one's own texts is an effective and cognitive process. Reflective work stimulates emotional feedback of the students, and improves the teaching process. It is important that specialists in linguistic didactics consider fiction as another means to the understanding of the foreign language environment, the first being staying among the native speakers in their own country. This fact proves that reading and understanding fiction supports the EFL competence high levels.

EFL competence comprises several components:

1) linguistic competence (knowledge of vocabulary and rules of linguistic constructions' building);

2) pragmatic competence (ability to make statements depending on the purpose during communication);

3) socio-linguistic competence (ability to use idioms and set-expressions, politeness formulas, i.e., ability to transform linguistic statements depending on the certain situation);

4) socio-cultural competence (extra-linguistic knowledge of the English-speaking countries);

5) strategic competence (ability to compensate the lack of linguistic knowledge right in the process of communication).

The EFL competence is formed as integrative development of the subject of communication during foreign language activity. Creative writing is a very complex and time-taking activity but it is very important in this respect.

\section{References}

Brovko, O. A. (2008). Innovations in the economy and the issues of the higher education. In Modernization of the system of higher education through evolutionary development: Proceedings, November 14, 2008, Moscow-Chelyabinsk. Part 3, pp 125-128.

Clarke, D. (2012). Insights into Social Constructivist Theory. Retrieved from http://www.aisr.org/school/newsflash/402

Gershanova, A. F. (2011). An Interdisciplinary Approach to the Study of the Fiction Text. In The Sixth International Scientific Conference "Language, Culture and Society": Proceedings. Russian Academy of Science. September 22-25, 2011, Moscow, pp. 71-72.

Ibsen, E. (1995). The Double Role of Fiction in Foreign-Language Learning: towards a creative methodology. In Selected Articles from the Creative English teaching Forum. Classroom Activities - Kral T. Editor. 1995, Washington DC, pp. 143-153.

Kenzhalinova, N. V. (2012). Teaching Foreign Discourse on the Example of Writing an Application letter by the Exchange Students. The fifth International Conference "Topical Issues of Linguistics and Lingual didactics of a Target language": Proceedings. Peoples' Friendship University of Russia. 2012, Moscow, pp. 41-43.

Mikhaleva, L. V., \& Kuznetcova, E. M. (2014). Educational Environment as the Means of Linguistic Education of Students. Higher Education in Russia, 3, 152-155. 
Osipov, P. N., \& Ziyatdinova, Y. N. (2015). Globalization as the Factor of Students' Development. Higher Education in Russia, 1, 140-146.

Sorokina, I. G. (2011). Teaching Writing in a Target Language at Linguistic University (Writing an Essay). In The Sixth International Scientific Conference "Language, Culture and Society": Proceedings. Russian Academy of Science. September 22-25, 2011, Moscow, pp. 316-317.

Sun-Keung, P. N. (2013). Globalization in One World: Impacts on Education in Different Nations. In Education in One World. Perspectives from different nations BCES Conference books (Vol. 11). Bulgarian Comparative Education Society. April, 2013, Sofia Bulgaria, pp. 17-25.

\section{Copyrights}

Copyright for this article is retained by the author(s), with first publication rights granted to the journal.

This is an open-access article distributed under the terms and conditions of the Creative Commons Attribution license (http://creativecommons.org/licenses/by/3.0/). 